\title{
Risk and Protective Factors in Cyberbullying: the Role of Family, Social Support and Emotion Regulation
}

\author{
N. Arató ${ }^{1} \cdot$ A. N. Zsidó ${ }^{1} \cdot$ A. Rivnyák ${ }^{1} \cdot$ B. Péley ${ }^{1}$ B. Lábadi ${ }^{1}$
}

Accepted: 10 May 2021 / Published online: 21 May 2021

(c) The Author(s) 2021

\begin{abstract}
Family and peer effects, as well as socio-emotional skills, are considered to have an essential role in cyberbullying. Although the dynamics of social factors and socio-emotional processes underlying cyberbullying are still open for research to further understand the direct and indirect relationships among the social factors (e.g., peers and family), socio-emotional skills (e.g. emotion regulation) and cyberbullying engagement. Thus, the aim of our study was to test models of cyberbullying perpetration and cybervictimization based on the role of family dynamics (cohesion, adaptability and communication), social support (from family and friends) and emotion regulation difficulties. One thousand, one hundred and five students (552 males, aged 11-19 years) participated in our research. We used self-report questionnaires to measure cyberbullying perpetration and cybervictimization, family functioning, perceived social support and emotion regulation difficulties. Our main findings support the crucial role of family and peers in cyberbullying engagement during adolescence. Perceived support from friends and family serve as protective factors against cybervictimization. Further, perceived support from friends and balanced family cohesion are protective factors against cyberbullying perpetration. On the other hand, emotion regulation difficulties appear to increase the risk of both cyberbullying perpetration and cybervictimization. Our findings confirm and extend the research on the role of family and peer effects, as well as emotion regulation in cyberbullying engagement. Moreover, our results have important implications for prevention and intervention programs involving family and peer support.
\end{abstract}

Keywords Family functioning $\cdot$ Social support $\cdot$ Emotion regulation $\cdot$ Structural equation modelling $\cdot$ Cyberbullying

\section{Introduction}

As the importance of peer relationships increases throughout adolescence (Hartup \& Stevens, 1997), youngsters seek for relationships not only in their offline environment but also on the Internet (Gross, 2004; Valkenburg \& Peter, 2007; Wolak et al., 2003). With the increased exposure to social

N. Arató

arato.nikoca@gmail.com

A. N. Zsidó

zsido.andras@pte.hu

A. Rivnyák

rivnyak.adrienn@pte.hu

B. Péley

peley.bernadette@pte.hu

B. Lábadi

labadi.beatrix@pte.hu

1 Institute of Psychology, University of Pécs, Pécs, Hungary media, like sharing pictures, videos and updating statuses about themselves, adolescents are at higher risk to engage in cyberbullying acts (Álvarez-García et al., 2015; Kowalski et al., 2014; Mishna et al., 2012; Walrave \& Heirman, 2011).

Cyberbullying is often identified as a subtype of traditional bullying taking place in a new context, i.e., the Internet (Li, 2007; Wang et al., 2010). Thus, the definitions describing cyberbullying, partly adapt Olweus' definitional criteria (1994) for traditional bullying, using 'imbalance of power', 'intentionality', and 'repetition' to differentiate cyberbullying acts from other types of aggression on the Internet (Berne et al., 2013; Nocentini et al., 2010; Slonje \& Smith, 2008; Spears et al., 2009). Further, the definitions of cyberbullying involve specific characteristics of cyberbullying as well (Berne et al., 2013; Nocentini et al., 2010; Slonje \& Smith, 2008; Spears et al., 2009). These unique characteristics include unlimited capacity of the Internet, the perpetrator's anonymity, the broad audience (Kwan \& Skoric, 2013) and its 24/7 nature (Kowalski \& Limber, 2007). Although, there is a lack of 
consensus about the definitional criteria of cyberbullying as not all cyberbullying incidents are characterized by all these aspects (Berne et al., 2013), for example, only app. $20-30 \%$ of cybervictims are not aware of the cyberbullying perpetrator's identity (Slonje \& Smith, 2008; Smith et al., 2008). Cyberbullying involvement affects both perpetrators' and victims' mental and physical health, as well as accounts for changes in their behaviour. The victims of cyberbullying experience negative affective states as a consequence of cyberbullying incidents (Alhujailli et al., 2020), i.e., they feel angry, anxious, afraid and ashamed (Ortega et al., 2012). Both cybervictims and cyberbullying perpetrators may suffer from symptoms of anxiety and depression (Didden et al., 2009; Perren et al., 2010; Skilbred-Fjeld et al., 2020; Ybarra \& Mitchell, 2004). Further, both cyberbullying perpetrators and cybervictims have poor physical health (Kowalski \& Limber, 2013), and there is an increased risk of selfinjury among them (Schneider et al., 2012). Cybervictims may also experience psychosomatic symptoms (Kowalski et al., 2014). Additionally, the behavioural consequences of cyberbullying involvement include substance abuse (Ybarra \& Mitchell, 2004), truancy, poor academic performance, decreased concentration and trespassing behaviours for both perpetrators and victims (Beran \& Li, 2005, 2007; Vazsonyi et al., 2012; Ybarra et al., 2007).

\section{The Role of Social Support in Cyberbullying Involvement}

Past studies have shown that social support might be an effective protective factor in mitigating the negative consequences associated with cyberbullying (Cho \& Yoo, 2017; Hellfeldt et al., 2020; Olenik-Shemesh \& Heiman, 2017). Social support is seen as a coping source provided by one's interpersonal relationships, which can help to endure stressful situations and to buffer against the negative effects of these (Cooke et al., 1988; Hirsch, 1981; McCubbin et al., 1980; Zimet et al., 1988). More specifically, family and peer support play an important role in the process whether adolescents are able to cope with cyberbullying and to reduce the associated harmful effects of cyberbullying and to seek help (Banerjee et al., 2010; Mesch, 2009; Thompson \& Smith, 2011). Previous studies demonstrated that both parental and peer social support can affect youngsters' aggressive emotional impulses (Dodge et al., 2007; Jenkins \& Demaray, 2012; López et al., 2008; Shahar \& Henrich, 2016) and their cyberbullying involvement (Baldry et al., 2015; Bayraktar et al., 2015; Calvete et al., 2010; Fanti et al., 2012; Fridh et al., 2015; Heerde \& Hemphill, 2018; Kowalski et al., 2014; Martins et al., 2016; Solecki et al., 2014; Wang et al., 2009; Williams \& Guerra, 2007). The poor perceived peer support increases the likelihood of involvement in both cyberbullying perpetration (Calvete et al., 2010; Baldry et al., 2015; Bayraktar et al., 2015; Fanti et al., 2012; Heerde \& Hemphill, 2018) and cybervictimization (Baldry et al., 2015; Fridh et al., 2015; Kowalski et al., 2014; Williams \& Guerra, 2007). Similar effect was observed with the perceived social support from family; the perception of poor parental support is strongly associated with both cyberbullying perpetration (Calvete et al., 2010; Fanti et al., 2012; Solecki et al., 2014; Wang et al., 2009) and cybervictimization (Fanti et al., 2012; Fridh et al., 2015; Kowalski et al., 2014; Martins et al., 2016; Williams \& Guerra, 2007). In sum, poor peer and family support are risk factors of cyberbullying involvement. However, the family factors can be further specified, as not only the support from the family but also the relationships among family members, the family's adaptation skills and the communication patterns of the family offer information on a family's functioning and influence (Olson, 2000).

\section{The Role of Family Communication, Cohesion and Adaptability in Cyberbullying Involvement}

Recently, many studies have begun to investigate how family variables affect adolescents' subsequent involvement in cyberbullying behaviours. Such a family variable is family communication that provides information on the family members' listening and speaking skills, self-disclosure, respect and regard (Olson, 2000). The family communication plays a role in preventing cyberbullying, both in terms of perpetration and victimization. Positive, open and empathetic family communication seems to be a protective factor and reducing the risk of involvement in cyberbullying behaviours (Buelga et al., 2017; Buelga et al., 2016; Cross et al., 2015; Fanti et al., 2012; Mesch, 2009; Perren et al., 2012). Whereas, negative, offensive and avoidant communication increases the risk of both cyberbullying perpetration and cybervictimization (Buelga et al., 2017; Buelga et al., 2016; Elgar et al., 2014; Larrañaga, et al., 2016). There is also an agreement among the findings derived from studies on family cohesion (Buelga et al., 2017; Ortega-Barón et al., 2016). Family cohesion is 'the emotional bonding that family members have towards one another' (Olson, 2000, pp. 145). Poor, dysfunctional, conflictual family relationships and lack of emotional link among family members increase the problems of social adjustment during adolescence, which contributes to the odds of engagement in cyberbullying perpetration (Buelga et al., 2017; Hemphill \& Heerde, 2014; Ybarra \& Mitchell, 2004). Likewise, family cohesion is also a considered predictor of cybervictimization, and adolescents becoming victims tend to obtain lower scores on family cohesion scales (Ortega-Barón et al., 2016). Relatively, little is known about the relationship between family adaptability and cyberbullying. Adaptability is a 'family's ability to change its power structure, role relationships and rules' 
(Place et al., 2005, pp. 215.) in response to the adolescent member's developmental needs. It seems that the characteristics of family adaptability may affect youngsters' aggressive behaviour (Steinberg, 2000). Indeed, if the family's hierarchical system, rules and roles do not change accordingly to the developmental changes and needs of the adolescent member, it may increase the likelihood of adolescents' delinquent (Cashwell \& Vacc, 1996), as well as aggressive behaviour (Pérez-Fuentes et al., 2019). In sum, the growing body of studies investigating the role of the dynamic family variables has found evidence that family communication and family cohesion are deeply associated with the adolescents' cyberbullying behaviour. These studies have not explored the role of mediating factors; however, there is a possibility that there are factors that mediate the link between the family and the peer variables and cyberbullying involvement. The investigation of mediating variables could offer statistical advantages, e.g., the bootstrap approach provides greater statistical power (Mackinnon et al., 2004) and deeper understanding about the underlying dynamics (Baron \& Kenny, 1986). Such a mediating variable that may carry the effect of peer and family factors might be emotion regulation that has already been shown to be having an effect on cyberbullying engagement.

\section{The Influence of Emotion Regulation on Cyberbullying Involvement}

Previous research shows that involvement in cyberbullying is associated more broadly with emotion regulation during adolescence (Baroncelli \& Ciucci, 2014; Den Hamer \& Konijn, 2016; Gianesini \& Brighi, 2015). Emotion regulation is a socio-emotional skill that is needed for successful social relationships (Gross \& John, 2003), social competence (Eisenberg \& Fabes, 1992), psychological well-being (Quoidbach et al., 2010) and regulating aggressive tendencies (Roberton et al., 2012). Negative and maladaptive emotion regulation strategies increase the risk of becoming both a perpetrator of cyberbullying (Baroncelli \& Ciucci, 2014; Den Hamer \& Konijn, 2016; Gianesini \& Brighi, 2015) and a cybervictim (Gianesini \& Brighi, 2015; Vranjes et al., 2018). Additionally, the relationship between emotion regulation strategies and the dynamics of cyberbullying might produce a vicious circle as the cyclic process model (Den Hamer \& Konijn, 2016) suggested: If cybervictimized youngsters use maladaptive emotion regulation strategies to cope with the negative emotions following cyberbullying incidents, this maladaptive coping enhances the likelihood of their subsequent cyberbullying behaviour on the Internet (Den Hamer \& Konijn, 2016). However, emotion regulation may not only have a direct link with cyberbullying: It may serve as the mediating factor between social factors and cyberbullying involvement, since its development is associated with both peer and family factors during adolescence.

\section{Emotion Regulation as a Possible Mediating Factor}

As peer relationships become more important during adolescence, adolescents have an impact on each other's developing emotion regulation (Steinberg \& Silk, 2002). The association between emotion regulation and peer relationships is twofold: Emotion regulation influences adolescents' social competences and functioning (Eisenberg \& Fabes, 1992; Gross \& John, 2003), as well as the development and maintenance of peer relationships (Sroufe et al., 1984). Also, adolescents might seek support from peers in emotionally distressing situations as a means of emotion regulation strategies (Gottman \& Mettetal, 1986). Further, youngsters regulate the intensity of the expression of emotions strategically to enhance the access to this social support (Dunn \& Brown, 1991). Through this mechanism, peers have an effect on the success or failure of emotion regulation strategies. Since there is supporting evidence on both the developmental link between peer support and emotion regulation and peer support's association with cyberbullying involvement (Cho \& Yoo, 2017; Hellfeldt et al., 2020; Olenik-Shemesh \& Heiman, 2017), emotion regulation may possibly mediate the relationship between peer support and cyberbullying involvement.

Further, children who grow up in a dysfunctional family with low emotional communication are not given with a model of how to accurately understand and respond to emotional situations. These children are not encouraged to verbalize and display their feelings in an adaptive way; therefore, they do not learn understanding and regulating their own emotions (Eisenberg et al., 1998; Rutherford et al., 2015). However parents set the groundwork for emotion regulation across childhood; in adolescence, the family still influences youngsters' emotion regulation. For example, the way how parents balance between their supervision and the adolescents' greater needs for autonomy is a guide for interpreting and determining how to regulate their feelings (Morris et al., 2007). Based on this developmental link and the studies' (Banerjee et al., 2010; Mesch, 2009; Thompson $\&$ Smith, 2011) results showing supporting evidence on the role of parental factors in adolescents' coping with the emotional consequences of cyberbullying, emotion regulation may serve as the mediating factor that carries the effect of family factors on cyberbullying involvement.

\section{Aim and Hypotheses}

Taken together, the above research suggests that family and peer factors - particularly those associated with emotions 
and communication-may influence both cyberbullying perpetration and cybervictimization. Further, there is an established link between cyberbullying involvement and youth emotion regulation. Although, it is unclear, whether emotion regulation would act as a mediator in the relationship between family functioning, peer support and adolescent cyberbullying involvement. The goal of our study was to examine the direct and indirect effects, through emotion regulation difficulties, of family functioning factors (cohesion, adaptability and communication), perceived emotional parental and peer support in cyberbullying involvement. We tested models of cyberbullying perpetration and cybervictimization using these variables. First, we hypothesized that maladaptive family adaptability, unbalanced levels of family cohesion and conflictual communication style among family members increased the risk of both cyberbullying perpetration and cybervictimization. In addition, we assumed that these family characteristics had both a direct and an indirect effect on both cyberbullying perpetration and cybervictimization through emotion regulation difficulties. Additionally, we also hypothesized that perceived emotional peer and parental social support had an effect on cyberbullying involvement: Poor peer and parental support led to both cyberbullying perpetration and cybervictimization. At last, we expected that poor emotional parental and peer support also had a direct and an indirect effect with the mediating role of emotion regulation difficulties on both cyberbullying perpetration and cybervictimization.

\section{Materials and Methods}

\section{Participants}

One thousand, one hundred and thirty secondary school students participated in the study (561 men, 569 women, age range= $11-19$ years, mean age $=15.23, \mathrm{SD}=1.71)$. However, 25 participants were removed from the database because of missing data. After the removal, 1105 students' (552 men, 553 women) data was analysed in the study; they were aged between 11 and 19 years (mean age $=15.21, \mathrm{SD}=1.71$ ). A total of $1.7 \%$ of the participants was living in the capital, 9.1\% were living the chief town of a county, $57 \%$ were living in rural cities and $32.1 \%$ were living in villages. A total of $54.3 \%$ of the students were attending a high school, $12 \%$ were attending vocational school, $1.7 \%$ was attending technical college, and $22.9 \%$ were attending elementary school. In case of $9 \%$ of the participants, there was no information on the type of school. It is important to note that the sample was not representative of the country's adolescent population. Ethical approval in conducting this study was granted from the Hungarian United Ethical Review Committee for Research in Psychology (reference number: 2019-99).

\section{Materials}

We used quantitative correlational design by means of four anonymous self-report questionnaires (For the mean scores, standard deviations and Cronbach's alphas, see Table 1):

The European Cyberbullying Intervention Project Questionnaire (ECIPQ, Del Rey et al., 2015; trans. Arató et al., 2019) measures both cyberbullying perpetration and cybervictimization. It includes the cyberbullying criteria of repetition and the imbalance of power. The questionnaire measures cyberbullying perpetration with 11 items, e.g., 'I said nasty things to someone or called them names using texts or online messages', and it also measures cybervictimization with 11 items, e.g. 'Someone said nasty things to me or called me names using texts or online messages'. Participants answered on a 5 -point Likert scale $(0=$ never, $1=$ once or twice, $2=$ once a month, $3=$ once a week, $4=$ more times a week) to indicate how often they engage in cyberbullying behaviours or become victims of it. Higher scores meant that the participants engaged in cyberbullying more frequently. The original questionnaire was psychometrically tested with participants aged between 11 and 23 years in six European countries, showing adequate reliability (Cronbach's $\alpha$ of the cyberbullying perpetration factor $=.93$; Cronbach's $\alpha$ of the cybervictimization factor $=.97$; Del Rey et al., 2015). Both scales showed an adequate reliability on our sample as well (Cronbach's $\alpha$ of the cyberbullying perpetration factor $=$ .91; Cronbach's $\alpha$ of the cybervictimization factor $=.90$ ).

The Difficulties in Emotion Regulation Questionnaire (DERS, Gratz \& Roemer, 2004; trans. Kökönyei, 2008) evaluates difficulties in emotion regulation consisting of 36 items. The DERS measures difficulties in the following aspects of emotion regulation: (a) acceptance of emotions (non-acceptance); (b) ability to engage in goal-directed behaviour when experiencing negative emotions (goals); (c) refraining from impulsive behaviour (impulse); (d) awareness of emotions (awareness); (e) accessing effective emotion regulation strategies when experiencing negative emotions (strategies); (f) understanding of emotions (clarity). Participants answered on a 5 -point Likert scale $(1=$ almost never, $0-10 \%$; $2=$ sometimes, $11-35 \%$; $3=$ about half the time, $36-65 \%$; $4=$ most of the time, $66-90 \%$; $5=$ almost always, 91-100\%) to indicate how often the different emotion regulation difficulties characterize them. If participants scored high on the subscales, it meant that they had difficulties regulating their emotions during distressing times. The original questionnaire was psychometrically analysed with participants aged between 18 and 55 years, all the subscales showing adequate reliability (Cronbach's $\alpha$ of non-acceptance $=.85$, Cronbach's $\alpha$ of goals $=.89$, Cronbach's $\alpha$ of impulse $=.86$, Cronbach's $\alpha$ of awareness $=.80$, Cronbach's $\alpha$ of strategies $=.88$, Cronbach's $\alpha$ of clarity $=.84$; Gratz \& Roemer, 2004). The DERS subscales 
Table 1 Descriptive statistics

\begin{tabular}{lcccccc}
\hline & Score range & Mean score & Std. deviation & $\begin{array}{l}\text { Cronbach's } \\
\text { alpha }\end{array}$ & Skewness (std. error) & Kurtosis (std. error) \\
\hline Cyberbullying perpetration (ECIPQ) & & & & & \\
Cybervictimization (ECIPQ) & $0-44$ & 12.79 & 5.27 & .91 & $2.24(0.07)$ & $14.53(0.15)$ \\
Non-acceptance (DERS) & $0-44$ & 14.51 & 6.22 & .90 & $1.55(0.07)$ & $6.29(0.15)$ \\
Goals (DERS) & $6-30$ & 12.91 & 5.63 & .86 & $0.81(0.07)$ & $0.19(0.15)$ \\
Impulse (DERS) & $5-25$ & 14.40 & 4.88 & .82 & $0.12(0.07)$ & $-0.67(0.15)$ \\
Awareness (DERS) & $6-30$ & 14.62 & 5.50 & .83 & $0.51(0.07)$ & $-0.40(0.15)$ \\
Strategies(DERS) & $6-30$ & 16.87 & 4.88 & .77 & $0.25(0.07)$ & $-0.16(0.15)$ \\
Clarity (DERS) & $8-40$ & 19.00 & 7.42 & .87 & $0.62(0.07)$ & $-0.30(0.15)$ \\
Enmeshed family cohesion (FACES IV) & $5-25$ & 11.26 & 4.18 & .77 & $0.43(0.07)$ & $-0.37(0.15)$ \\
Balanced family cohesion (FACES IV) & $7-35$ & 14.81 & 4.18 & .67 & $0.63(0.07)$ & $0.85(0.15)$ \\
Disengaged family cohesion (FACES IV) & $7-35$ & 28.24 & 4.94 & .83 & $-1.15(0.07)$ & $1.61(0.15)$ \\
Rigid family adaptability (FACES IV) & $7-35$ & 13.51 & 4.59 & .77 & $1.21(0.07)$ & $1.99(0.15)$ \\
Balanced family adaptability (FACES IV) & $7-35$ & 16.01 & 4.80 & .73 & $0.56(0.07)$ & $1.05(0.15)$ \\
Chaotic family adaptability (FACES IV) & $7-35$ & 25.33 & 5.12 & .78 & $-0.59(0.07)$ & $0.30(0.15)$ \\
Family communication (FACES IV) & $7-35$ & 12.68 & 4.45 & .72 & $1.31(0.07)$ & $2.73(0.15)$ \\
Family satisfaction (FACES IV) & $10-50$ & 37.88 & 7.01 & .85 & $-0.80(0.07)$ & $0.63(0.15)$ \\
Social support from friends (MSPSS) & $10-50$ & 36.19 & 8.58 & .93 & $-0.61(0.07)$ & $0.20(0.15)$ \\
Social support from family (MSPSS) & $4-28$ & 23.55 & 4.86 & .91 & $-1.52(0.07)$ & $2.41(0.15)$ \\
Social support from significant other (MSPSS) & $4-28$ & 23.49 & 5.16 & .92 & $-1.52(0.07)$ & $2.12(0.15)$ \\
\hline
\end{tabular}

showed adequate or near adequate reliability on our sample as well (Cronbach's $\alpha$ of non-acceptance $=.86$, Cronbach's $\alpha$ of goals $=.82$, Cronbach's $\alpha$ of impulse $=.83$, Cronbach's $\alpha$ of awareness $=.77$, Cronbach's $\alpha$ of strategies $=.87$, Cronbach's $\alpha$ of clarity $=.77$ ).

The Family Adaptability and Cohesion Evaluation Scale IV (FACES IV, Olson, 2011; trans. Vargha \& Tóth, 2007) is a self-report measure to assess the following family dimensions: cohesion, flexibility, communication and satisfaction consisting of 62 items. The FACES IV assesses balanced cohesion and flexibility as well as the high and low extremes of both cohesion (enmeshed and disengaged) and flexibility (rigid and chaotic). Participants answer on a five-point Likert scale ( $1=$ strongly disagree; $2=$ generally disagree; $3=$ undecided; $4=$ generally agree; $5=$ strongly agree). Higher scores on the subscales meant that the specific family functioning type (e.g. enmeshed family cohesion) characterized the participants' family. Moreover the FACES IV contains two additional scales: Family Communication Scale and Family Satisfaction Scale. Both scales consist of 10 items, and participants implied on a five-point Likert scale ( $1=$ very dissatisfied; $2=$ somewhat dissatisfied; $3=$ generally satisfied; $4=$ very satisfied; $5=$ extremely satisfied) to what extent they are satisfied with the functioning of the family and communication among family members. Higher scores on these two scales meant that the participants were satisfied with the family's communication style and with their family's overall functioning. The original scale was psychometrically tested with a sample aged between 18 and 59 showing adequate reliability for all the subscales (Cronbach's $\alpha$ of enmeshed cohesion $=.77$, Cronbach's $\alpha$ of disengaged cohesion $=.87$, Cronbach's $\alpha$ of balanced cohesion $=.89$, Cronbach's $\alpha$ of chaotic adaptability $=.86$, Cronbach's $\alpha$ of balanced adaptability $=.84$, Cronbach's $\alpha$ of rigid adaptability $=.82$; Olson, 2011). However, there were previous studies (Baiocco et al., 2013; Koutra et al., 2013) that adapted the scale with adolescents. In both studies, lower than adequate reliability scores were found for the subscales: Baiocco et al. (2013) found reliability scores ranging from .63 to .73 , disengaged showing the lowest score. On the other hand, in Koutra and colleagues' study (2013), the reliability scores ranged from .59 to .79 , enmeshed cohesion showing the lowest reliability score. Most of the subscales showed adequate or near adequate reliability in our sample (Cronbach's $\alpha$ of disengaged cohesion $=.77$, Cronbach's $\alpha$ of balanced cohesion $=.83$, Cronbach's $\alpha$ of chaotic adaptability $=.72$, Cronbach's $\alpha$ of balanced adaptability $=.78$, Cronbach's $\alpha$ of rigid adaptability $=.73$, Cronbach's $\alpha$ of communication $=.85$, Cronbach's $\alpha$ of satisfaction $=.93$ ), but one scale, i.e. enmeshed cohesion, showed lower reliability (Cronbach's $\alpha=.67$ ).

The Multidimensional Scale of Perceived Social Support (MSPSS, Zimet et al., 1988 trans. Papp-Zipernovszky et al., 2017) is a 12-item scale that assesses perceived support from three sources: family, friends and significant other. Participants answered on a seven-point Likert scale (1=very strongly disagree; $7=$ very strongly agree) to indicate the level of perceived social support from the different sources. The higher scores meant that the participant perceived 
higher levels of social support from friends, family and/ or significant other. The original scale was tested psychometrically with adolescents showing adequate reliability (Cronbach's $\alpha$ of family $=.81$, Cronbach's $\alpha$ of friends $=$ .92 , Cronbach's $\alpha$ of significant other $=.83$; Zimet et al., 1990). The scale showed adequate reliability scores on our sample as well (Cronbach's $\alpha$ of family $=.92$, Cronbach's $\alpha$ of friends $=.89$, Cronbach's $\alpha$ of significant other $=.88$ ).

\section{Procedure}

After the ethical approval was granted, the study was taking place in the second semester of the 2018/2019 school year. The population of the study was Hungarian secondary school students, so we have sent out e-mails with our research proposal to 12 secondary schools. Nine schools agreed to participate in the research, but in the end, only seven schools' students participated in the study. The choice of schools was based on accessibility and the university's connections. After the school principal agreed to participate in the study, the schools' head teachers were informed that they could volunteer to participate in the study with their classes. In two schools, no head teacher applied voluntarily. In the remaining seven schools, research assistants recruited students in the volunteer head teachers' classes during school hours. The recruitment included a short introduction about the study (e.g. what the topic of the research was, what they had to do during the research), and the research assistants handed out the parental consent forms. Volunteering students could participate in the study if their parents gave informed consent. The study was conducted during school hours in the students' classroom with the supervision of their teachers and/or our research assistants (undergraduate students, Ph.D. students). The students completed the questionnaires anonymously by paper-pencil or online, via Google Forms after giving their informed consent to participate in the research.

\section{Statistical Analysis}

IBM SPSS Statistics 23 was used to analyse, whereas IBM SPSS Amos 20 was used to conduct the path analyses.

We created four cyberbullying groups to see the frequency of cyberbullying involvement in our sample using the mean scores and standard deviations (for the mean scores and standard deviation, see Table 1). Students were considered cyberbullies if they scored higher than the sum of the mean and one standard deviation on the cyberbullying perpetration scale of ECIPQ. Students scoring higher than the sum of the mean and one standard deviation on the cybervictimization scale of ECIPQ were considered cybervictims. Students scoring higher than the sum of the mean and one standard deviation on both cyberbullying and cybervictimization scales of the ECIPQ were considered bully-victims. At last, students who scored lower than the mean on both the cyberbullying perpetration and the cybervictimization scale of the ECIPQ were considered outsiders.

First, descriptive statistics were calculated (see Table 1). The skewness and kurtosis values showed that some of the variables were not normally distributed, i.e. cyberbullying perpetration (ECIPQ), cybervictimization (ECIPQ), social support from friends, family and a significant other (MSPSS), disengaged family cohesion, balanced family cohesion, rigid family adaptability and chaotic family adaptability (FACES IV). Although, with large sample sizes (> 30 or 40), parametric procedures can be used even if the data violates the normality assumption (Altman \& Bland, 1995; Elliott \& Woodward, 2007; Ghasemi \& Zahediasl, 2012). Consequently, first linear regression analyses with stepwise extension were used to find the variables that are significantly associated with cyberbullying perpetration and cybervictimization to include only these variables later, in the path analyses. A linear regression analysis with stepwise extension was conducted to determine the predictors of cyberbullying perpetration with difficulties in emotion regulation (non-acceptance, goals, impulse, awareness, strategies and clarity), perceived social support (friend and family support) and family functioning (enmeshed, disengaged and balanced cohesion, rigid, chaotic and balanced flexibility, communication and satisfaction) as independent variables. Another linear regression analysis with stepwise extension was used to test the predictors of cybervictimization as well with the same independent variables as previously. Based on the significant results of the linear regression analyses, path analyses were used to test models of cyberbullying perpetration and cybervictimization. Ninety-five per cent confidence intervals and bootstrapping with 2000 resamples were used. According to Hu \& Bentler (1999), the following criteria were used for the fitting indices: $\chi^{2} / \mathrm{df}<2$, RMSEA $<.06$, $\mathrm{NFI}>.95, \mathrm{TLI}>.95, \mathrm{CFI}>.95$.

\section{Results}

For the descriptive data, i.e. mean scores, standard deviations, reliability scores, skewness and kurtosis estimates, see Table 1. Based on the created cyberbullying groups, $1.6 \%$ of the students were involved in cyberbullying as perpetrators, $7.1 \%$ were victims of cyberbullying, $4.9 \%$ were bully-victims and $86.4 \%$ were not involved in cyberbullying. Table 2 provides information on how the four cyberbullying groups (cyberbullying perpetrators, cybervictims, bully-victims and outsiders) scored on the scales (DERS, FACES IV, MSPSS). 
Table 2 Descriptive data of the cyberbullying groups' scores on the DERS, FACES IV and MSPSS

\begin{tabular}{|c|c|c|c|c|}
\hline & $\begin{array}{l}\text { Cyberbullying Perpetrators } \\
(n=18) \mathrm{M}(\mathrm{SD})\end{array}$ & $\begin{array}{l}\text { Cybervictims }(n=78) \\
\mathrm{M}(\mathrm{SD})\end{array}$ & $\begin{array}{l}\text { Bully-victims }(n=54) \\
M(S D)\end{array}$ & $\begin{array}{l}\text { Outsiders } \\
(n=955) \\
\mathrm{M}(\mathrm{SD})\end{array}$ \\
\hline Cyberbullying perpetration (ECIPQ) & $21.61(3.35)$ & $13.92(2.29)$ & $28.37(8.71)$ & $11.65(3.27)$ \\
\hline Cybervictimization (ECIPQ) & $14.06(3.96)$ & $25.14(5.22)$ & $29.56(7.86)$ & $12.80(3.73)$ \\
\hline Non-acceptance (DERS) & $10.78(5.53)$ & $15.33(5.94)$ & $16.76(5.69)$ & $12.54(5.48)$ \\
\hline Goals (DERS) & $14.33(5.58)$ & $16.61(5.26)$ & $16.09(4.12)$ & $14.12(4.82)$ \\
\hline Impulse (DERS) & $14.67(5.30)$ & $17.64(5.61)$ & $18.80(4.55)$ & $14.14(5.38)$ \\
\hline Awareness (DERS) & $16.83(4.77)$ & $17.49(4.95)$ & $19.17(4.90)$ & $16.69(4.85)$ \\
\hline Strategies(DERS) & $17.44(6.74)$ & $24.42(8.54)$ & $23.81(6.35)$ & $18.31(7.11)$ \\
\hline Clarity (DERS) & $10.17(4.00)$ & $13.26(4.59)$ & $15.02(4.24)$ & $10.91(3.99)$ \\
\hline Enmeshed family cohesion (FACES IV) & $14.22(4.58)$ & $15.81(4.46)$ & $17.07(5.18)$ & $14.61(4.04)$ \\
\hline Balanced family cohesion (FACES IV) & $27.94(5.68)$ & $27.41(5.84)$ & $25.07(5.26)$ & $28.50(4.77)$ \\
\hline Disengaged family cohesion (FACES IV) & $14.67(3.76)$ & $14.87(5.34)$ & $16.00(5.08)$ & $13.23(4.45)$ \\
\hline Rigid family adaptability (FACES IV) & $14.89(5.09)$ & $17.33(4.28)$ & $17.56(5.03)$ & $15.84(4.79)$ \\
\hline Balanced family adaptability (FACES IV) & $25.00(4.74)$ & $23.69(6.10)$ & $22.09(4.95)$ & $25.65(4.96)$ \\
\hline Chaotic family adaptability (FACES IV) & $13.72(5.07)$ & $14.60(5.46)$ & $15.93(5.59)$ & $12.32(4.16)$ \\
\hline Family communication (FACES IV) & $34.83(9.76)$ & $35.90(8.73)$ & $33.57(6.81)$ & $38.34(6.68)$ \\
\hline Family satisfaction (FACES IV) & $36.17(8.48)$ & $33.78(9.54)$ & $33.52(8.37)$ & $36.53(8.47)$ \\
\hline Social support from friends (MSPSS) & $23.78(4.33)$ & $21.69(5.94)$ & $19.83(6.13)$ & $23.91(4.57)$ \\
\hline Social support from family (MSPSS) & $23.67(5.63)$ & $21.08(6.62)$ & $19.63(5.72)$ & $23.90(4.83)$ \\
\hline Social support from significant other (MSPSS) & $26.22(2.78)$ & $23.94(5.13)$ & $21.11(5.62)$ & $25.46(3.89)$ \\
\hline
\end{tabular}

\section{Determinants of Cyberbullying Perpetration}

According to the results of the linear regression analysis with stepwise extension, perceived friend support $(\beta=-14, p<$ $.001)$, enmeshed $(\beta=.12, p<.001)$ and balanced $(\beta=-.11$, $p<.001)$ family cohesion, difficulties in refraining from impulsive behaviour $(\beta=.10, p=.001)$ and in understanding of emotions $(\beta=.09, p=.01)$ accounted for $1 \%$ of the variance in cyberbullying perpetration $(F(1,1099)=7.11, p=$ $.01)$. Further, cyberbullying perpetration was most strongly affected by perceived friend support $(F(1,1103)=49.49, p=$ $<.001, \beta=-.21, p<.001)$, which accounted for $4.3 \%$ of the variance. (For more detailed results, see Table 3 ).

\section{Determinants of Cybervictimization}

According to the results of the linear regression analysis with stepwise extension, perceived support from friends ( $\beta=$ $-.11, p<.001)$ and family $(\beta=-0.15, p<.001)$, enmeshed family cohesion $(\beta=.14, p<.001)$, difficulties in refraining from impulsive behaviour $(\beta=.10, p=.01)$, in understanding of emotions $(\beta=.10, p=.003)$ and in accessing effective emotion regulation strategies when experiencing negative emotions $(\beta=.10, p=.01)$, accounted for $1 \%$ of the variance in cybervictimization $(F(1,1098)=7.37, p=.01)$. Further, difficulties in accessing effective emotion regulation strategies when experiencing negative emotions were most strongly affecting cybervictimization $(F(1,1103)=89.14, p<$ $.001, \beta=.27, p<.001$ ), which accounted for $7.5 \%$ of the variance. (For more detailed results, see Table 4).

\section{Model of Cyberbullying Perpetration}

The model, tested with path analysis, consisted of perceived social support from friends, balanced and enmeshed family cohesion as predictor variables and difficulties in refraining from impulsive behaviour and in understanding of emotions as mediating variables toward cyberbullying perpetration. The results show that the model fits the data well, $\chi^{2}(1)=$ 4.00, $p=.05$, RMSEA $=.05$ (90\% CI: $.01 ; .11)$, NFI $=.99$, $\mathrm{TLI}=.92, \mathrm{CFI}=.99$. Enmeshed family cohesion $(\beta=.01, p<$ $.01,95 \% \mathrm{CI}=.002 ; .02)$, balanced family cohesion $(\beta=-.02$, $p<.001,95 \% \mathrm{CI}=-.04 ;-.01)$ and perceived friend support $(\beta=-.02, p<.01,95 \% \mathrm{CI}=-.04 ;-.01)$ had significant total indirect effects on cyberbullying perpetration. Figure 1 shows the standardized path coefficients and standardized $R$ squared estimates. The relationships were significant, except for the association between enmeshed family cohesion and difficulties in understanding of emotions $(\beta=.06, p=.06)$. The specific indirect effect of perceived friend support was mediated by difficulties in refraining from impulsive behaviour $(\beta=-.01, p=.01)$. Perceived friend support also had a specific indirect effect on cyberbullying perpetration through difficulties in understanding of emotions $(\beta=-.01, p=.01)$. 
Table 3 Results of linear regression analyses with stepwise extension with cyberbullying perpetration as dependent variable and family factors, perceived social support and difficulties with emotion regulation as independent variables

\begin{tabular}{llllll}
\hline & $R^{2}$ & $\mathrm{~F}$ & $\mathrm{df}$ & \multicolumn{1}{l}{$\beta$} & $\mathrm{t}$ \\
\hline Model 1 & & & & & \\
Friend support & .04 & $49.49^{* *}$ & 1,1103 & $-.21^{* *}$ & $-7.04^{* *}$ \\
Model 2 & & & & & \\
Friend support & .02 & $27.79^{* *}$ & 1,1102 & $-.19^{* *}$ & $-6.41^{* *}$ \\
Impulse & & & & $.16^{* *}$ & $5.27^{* *}$ \\
Model 3 & & & & & \\
Friend support & .01 & $9.51^{* *}$ & 1,1101 & $-.19^{* *}$ & $-6.31^{* *}$ \\
Impulse & & & & $.15^{* *}$ & $5.03^{* *}$ \\
Enmeshed cohesion & & & & $.09^{* *}$ & $3.08^{* *}$ \\
Model 4 & & & & & \\
Friend support & .01 & $13.81^{* *}$ & 1,1100 & $-.15^{* *}$ & $-4.72^{* *}$ \\
Impulse & & & & $.14^{* *}$ & $4.65^{* *}$ \\
Enmeshed cohesion & & & & $.12^{* *}$ & $3.97^{* *}$ \\
Balanced cohesion & & & & $-.12^{* *}$ & $-3.72^{* *}$ \\
Model 5 & & & & & \\
Friend support & .01 & $7.11^{*}$ & 1,1099 & $-.14^{* *}$ & $-4.55^{* *}$ \\
Impulse & & & & $.10^{* *}$ & $3.21^{* *}$ \\
Enmeshed cohesion & & & & $.12^{* *}$ & $3.93^{* *}$ \\
Balanced cohesion & & & & $-.11^{* *}$ & $-3.54^{* *}$ \\
Clarity & & & & $.09^{*}$ & $2.67^{*}$ \\
\hline
\end{tabular}

$* p<.05 ; * * p<.01$

The specific indirect effect of balanced family cohesion was also mediated by both difficulties in refraining from impulsive behaviour $(\beta=-.01, p<.01)$ and difficulties in understanding of emotions $(\beta=-.01, p=.01)$. The specific indirect effect of enmeshed family cohesion was mediated by difficulties in refraining from impulse behaviour $(\beta=.01$, $p<.01)$.

\section{Model of Cybervictimization}

The model, tested with path analysis, consisted of perceived social support from friends and family and enmeshed family cohesion as predictor variables and difficulties in refraining from impulsive behaviour, in understanding of emotions and in accessing effective emotion regulation strategies when experiencing negative emotions as mediating variables toward cybervictimization. The results show that the model fits the data well, $\chi^{2}(4)=5.72, p=.22$, RMSEA $=.02(90 \%$ CI: $.00 ; .05)$, NFI $=.99$, TLI $=.99, \mathrm{CFI}=.99$. Perceived support from family $(\beta=-.07, p=.001,95 \% \mathrm{CI}=-.11 ;-.05)$ and enmeshed family cohesion $(\beta=.04, p<.001,95 \% \mathrm{CI}=$ $.02 ; .06)$ had a significant total indirect effect on cybervictimization. Perceived support from friends had only a direct effect on cybervictimization, as the relationship was insignificant between perceived friend support and difficulties in refraining from impulsive behaviour $(\beta=-.06, \mathrm{p}=.10)$, difficulties in accessing effective emotion regulation strategies when experiencing negative emotions $(\beta=-.03, p=.48)$ and difficulties in understanding of emotions $(\beta=-.03, p=$ .30). Figure 2 shows the standardized path coefficients and standardized $R$ squared estimates. The specific indirect effect of perceived social support from family was mediated by difficulties in accessing effective emotion regulation strategies $(\beta=-.03, p=.01)$, by difficulties in understanding of emotions $(\beta=-.03, p=.01)$ and by difficulties in refraining from impulsive behaviour $(\beta=-.02, p=.01)$. The specific indirect effect of enmeshed family cohesion was mediated by difficulties in accessing effective emotion regulation strategies when experiencing negative emotions $(\beta=.02, p<.01)$, by difficulties in understanding emotions $(\beta=.01, p=.01)$ and by difficulties in refraining from impulsive behaviour $(\beta=.02, p=.01)$.

Table 4 Results of linear regression analyses with stepwise extension with cybervictimization as dependent variable and family factors, perceived social support and difficulties with emotion regulation as independent variables

\begin{tabular}{|c|c|c|c|c|c|}
\hline & $R^{2}$ & $\mathrm{~F}$ & df & $\beta$ & $\mathrm{t}$ \\
\hline \multicolumn{6}{|l|}{ Model 1} \\
\hline Strategies & .08 & $89.14 * *$ & 1,1103 & $.27 * *$ & $9.44 * *$ \\
\hline \multicolumn{6}{|l|}{ Model 2} \\
\hline Strategies & .03 & $38.65^{* *}$ & 1,1102 & $.25^{* *}$ & $8.65^{* *}$ \\
\hline Friend support & & & & $-.18 * *$ & $-6.22 * *$ \\
\hline Model 3 & $\mathrm{R}^{2}$ & $\mathrm{~F}$ & df & $\beta$ & $\mathrm{t}$ \\
\hline Strategies & .01 & $15.24 * *$ & 1,1101 & $.19 * *$ & $5.67 * *$ \\
\hline Friend support & & & & $-.17 * *$ & $-5.94 * *$ \\
\hline Clarity & & & & $.13 * *$ & $3.90 * *$ \\
\hline \multicolumn{6}{|l|}{ Model 4} \\
\hline Strategies & .01 & $13.50 * *$ & 1,1100 & $.18 * *$ & $5.37 * *$ \\
\hline Friend support & & & & $-.17 * *$ & $-5.84 * *$ \\
\hline Clarity & & & & $.13 * *$ & $3.97 * *$ \\
\hline Enmeshed cohesion & & & & $.10 * *$ & $3.68 * *$ \\
\hline \multicolumn{6}{|l|}{ Model 5} \\
\hline Strategies & .02 & $20.08 * *$ & 1,1099 & $.15^{* *}$ & $4.57 * *$ \\
\hline Friend support & & & & $-.12 * *$ & $-3.78 * *$ \\
\hline Clarity & & & & $.11 * *$ & $3.41 * *$ \\
\hline Enmeshed cohesion & & & & $.14 * *$ & $4.72 * *$ \\
\hline Family support & & & & $-.15^{* *}$ & $-4.48 * *$ \\
\hline \multicolumn{6}{|l|}{ Model 6} \\
\hline Strategies & .01 & $7.37 * *$ & 1,1098 & $.10^{*}$ & $2.54 *$ \\
\hline Friend support & & & & $-.11 * *$ & $-3.67 * *$ \\
\hline Clarity & & & & $.10^{* *}$ & $2.96 * *$ \\
\hline Enmeshed cohesion & & & & $.14^{* *}$ & $4.66^{* *}$ \\
\hline Family support & & & & $-.15^{* *}$ & $-4.55^{* *}$ \\
\hline Impulse & & & & $.10^{* * *}$ & $2.72 * *$ \\
\hline
\end{tabular}

${ }^{*} p<.05 ; * * p<.01$ 
Fig. 1 Model of cyberbullying perpetration. $* p<.05 ; * * p<.01$

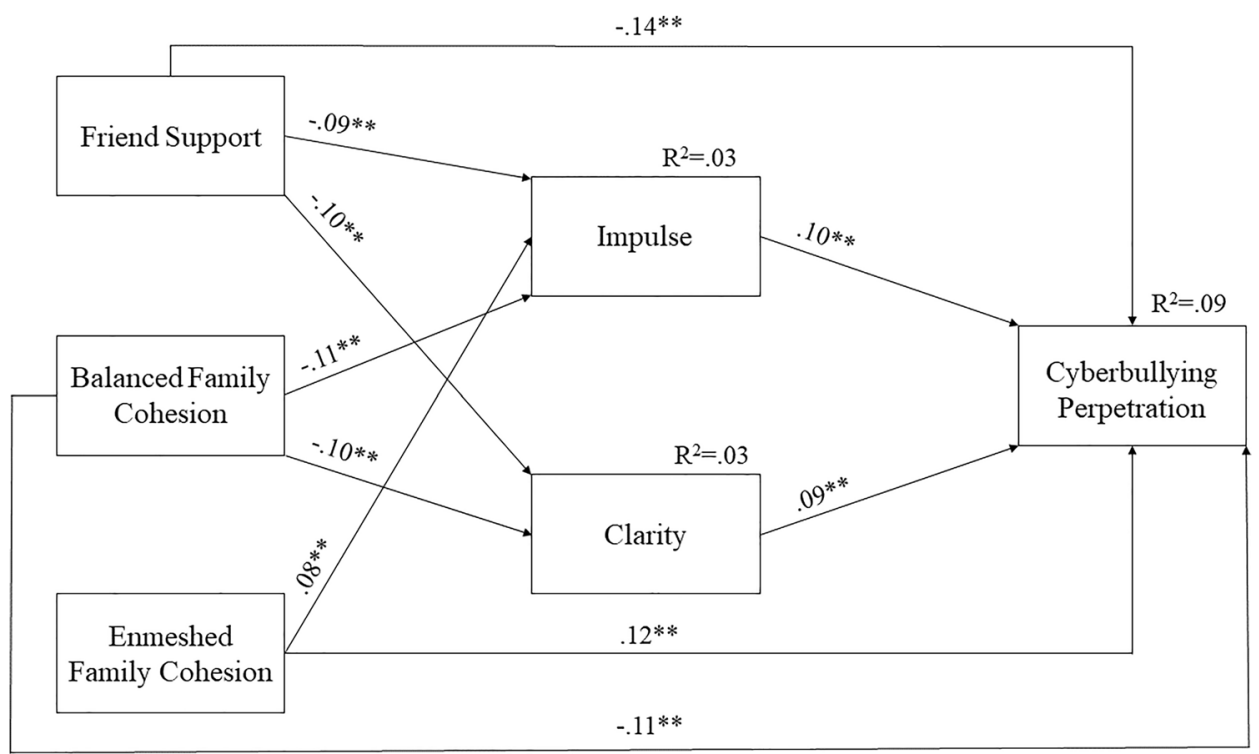

\section{Discussion}

The main goal of our study was to examine the role of family factors (cohesion, adaptability and communication), perceived parental and peer support and difficulties in emotion regulation on cyberbullying perpetration and cybervictimization. Our results supported models for both cyberbullying perpetration and cybervictimization: Enmeshed family cohesion and difficulties in refraining from impulsive behaviour and in understanding of emotions are risk factors for both cyberbullying perpetration and cybervictimization. Difficulties in accessing effective emotion regulation strategies when experiencing negative emotions are a risk factor for only cybervictimization. Further, perceived support from friends is a protective factor for both cyberbullying perpetration and cybervictimization. Perceived support from family is a protective factor for cybervictimization, whereas balanced family cohesion is a protective factor against cyberbullying perpetration. According to our results, family adaptability and communication have no role in cyberbullying perpetration and cybervictimization.

Enmeshed family cohesion is a risk factor for cyberbullying perpetration; it affected cyberbullying behaviour directly and also indirectly through difficulties in refraining from impulsive behaviour. Based on the results of earlier research (Buelga et al., 2017; Hemphill \& Heerde, 2014; Morris
Fig. 2 Model of cybervictimization. $* p<.05 ; * * p<.01$

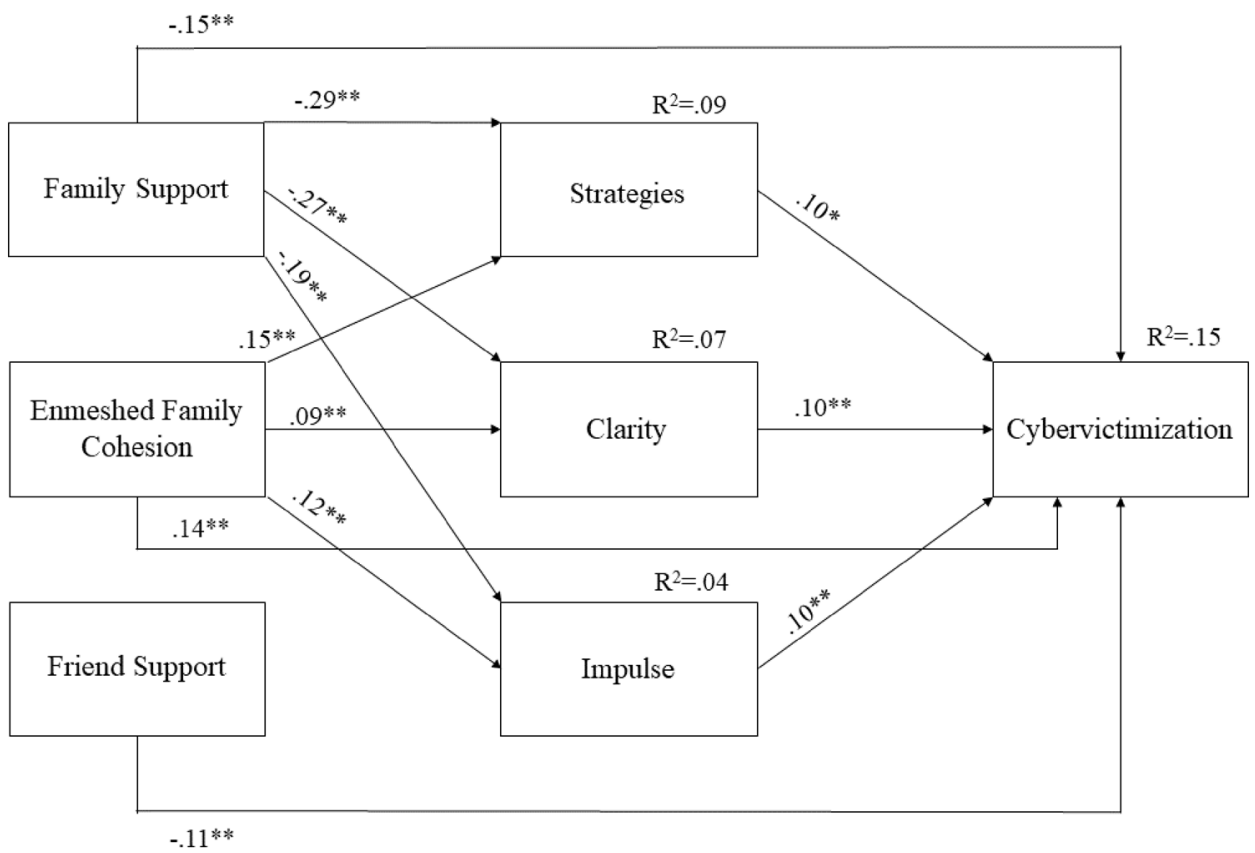


et al., 2007; Ybarra \& Mitchell, 2004), family relationships influence both the development of emotion regulation and involvement in cyberbullying behaviours. According to these results, poor, dysfunctional family relationships and lack of emotional link among family members contribute to cyberbullying perpetration (Buelga et al., 2017; Hemphill \& Heerde, 2014; Ybarra \& Mitchell, 2004). On the contrary, our results showed that a different type of family cohesion-enmeshed family cohesion-increased the chance of cyberbullying perpetration. In families with enmeshed family cohesion, there is an extreme amount of emotional closeness in the family, the family members are extremely dependent, and there is a lack of personal separateness, little private space. This pattern of family relationships also had a negative effect on the adolescents' impulse control, and this emotion regulation difficulty contributed to cyberbullying behaviour. An explanation of this result might be that this closeness among family members is the result of a maladaptive adaptation from the family to the adolescent member's need for more autonomy and independence. Consequently, adolescents use the Internet as an escape from this dependence among family members, to practice control and autonomy, and youngsters cyberbully others with the purpose to canalize their unregulated impulses. Our results also supported that balanced cohesion, when the family is able to adapt flexibly to the adolescent's needs and the adolescent is able to be both independent from the family and connected to it, is a protective factor against cyberbullying perpetration.

Enmeshed family cohesion is also a risk factor in cybervictimization. This type of family cohesion had direct effect and indirect effect through difficulties in refraining from impulsive behaviour, in understanding of emotions and in using effective emotion regulation strategies when experiencing negative emotions on cybervictimization. Previous studies demonstrated that balanced family cohesion might be a protective factor against cybervictimization (Buelga et al., 2017; Ortega-Barón et al., 2016; Taiariol, 2010), and emotion regulation was suggested to play a role in cybervictimization (Gianesini \& Brighi, 2015). Our model also supported these previous results as the extreme emotional closeness and dependence among family members - an unbalanced form of family cohesion-made youngsters vulnerable to cyberbullying on the Internet and affected their emotion regulation development negatively. As in these types of families there are no boundaries, no private spaces, youngsters from these families might share videos, pictures, comments and personal information without boundaries on the Internet, and this unlimited sharing makes them more vulnerable to cybervictimization (Álvarez-García et al., 2015; Kowalski et al., 2014; Mishna et al., 2012; Walrave \& Heirman, 2011). Further, in these types of families, adolescents might have less individual resources which can lead to the emotion regulation difficulties-ineffective emotion regulation strategies, uncontrollable impulses - and this can cause a higher degree of exposure to cybervictimization (Buelga et al., 2017; Van Dijk et al., 2014). In sum, our results showed both the risk and protective characteristics of relationships among family members.

Friend support is a protective factor against cyberbullying. Poor perceived peer support not only directly increased the chance of becoming a cyberbullying perpetrator but also had an indirect effect on cyberbullying through emotion regulation difficulties like difficulties in refraining from impulsive behaviour and in understanding of emotions. It was previously suggested that peers have an effect on the developing emotion regulation strategies during adolescence (Steinberg $\&$ Silk, 2002), and ineffective emotion regulation influences the involvement in cyberbullying perpetration (Baroncelli \& Ciucci, 2014; den Hamer \& Konijn, 2016; Gianesini \& Brighi, 2015). Further, earlier research (Baldry et al., 2015; Bayraktar et al., 2015; Calvete et al., 2010; Fanti et al., 2012; Heerde \& Hemphill, 2018) supported that poor peer support increases the chance of becoming a perpetrator of cyberbullying. In our study, we managed to combine these factors into a model. Our results showed a pattern of perceived peer support and difficulties in refraining from impulsive behaviour and in understanding of emotions underlying cyberbullying perpetration. An interpretation of this model might be that in the absence of supporting peer relationships as a means of emotion regulation, adolescents are not able to adaptively regulate their impulses and understand their emotions. Consequently, they turn to cyberbullying to deal with these negative emotional states through aggressive behaviours.

Additionally, perceived social supports from friends and family are protective factors against cybervictimization. On the other hand, peer support had only a direct effect on cybervictimization, and social support from family had both direct and indirect effects through difficulties in refraining from impulsive behaviour, in using effective emotion regulation strategies when experiencing negative emotions and in understanding of emotions. Previous studies (Baldry et al., 2015; Fanti et al., 2012; Fridh et al., 2015; Martins et al., 2016; Kowalski et al., 2014; Williams and Guerra, 2007) found that both poor parental support and lack of peer support increase the likelihood of cybervictimization. Our model also supported these results; furthermore, on account of perceived parental support, we found a dynamic effect through ineffective emotion regulation. All in all, in absence of parental support that helps the development of emotion regulation during adolescence (Morris et al., 2007), ineffective emotion regulation makes youngsters vulnerable to cybervictimization (Gianesini \& Brighi, 2015). Also, marginalized adolescents-who experience poor peer support—are more endangered to become cybervictimized. 
At last, emotion regulation difficulties are risk factors in both cyberbullying perpetration and cybervictimization. This is in line with previous findings (Baroncelli \& Ciucci, 2014; Den Hamer \& Konijn, 2016; Gianesini \& Brighi, 2015) showing that cyberbullying perpetrators, as well as cybervictims, have difficulties with regulating their affective states. Furthermore, our findings demonstrated specific emotion regulation difficulties that have both direct and mediating effects on cyberbullying engagement. Cyberbullying perpetrators have difficulties in refraining from impulsive behaviours and in understanding emotions. As they are unable to process their emotions adaptively, they might use cyberbullying behaviours as means to canalize their unregulated emotions to an external subject. On the other hand, difficulties in refraining from impulsive behaviour, in understanding of emotions and in accessing effective emotion regulation strategies when experiencing negative emotions increase the risk of cybervictimization. Adaptive emotion regulation strategies contribute to better social competence and functioning (Eisenberg \& Fabes, 1992; Gross \& John, 2003, Sroufe et al., 1984). Lacking adaptive social skills, youngsters might behave inadequately on the Internet (e.g. by limitlessly sharing pictures and/or videos); therefore, their behaviour might result in greater disclosure and increased risk of cybervictimization (Álvarez-García et al., 2015; Kowalski et al., 2014).

\section{Limitations}

Some limitations of our study shall be noted: First of all, there was no pilot study conducted. Therefore, we do not have information on whether the questions and items (e.g. DERS' items) were understandable for the participating adolescents. On account of opportunity sampling, our sample is not representative of the country's adolescent population. Although anonymity should have lowered the risk of socially desirable answers, adolescents might have underreported their involvement in cyberbullying. The low frequency of cyberbullying involvement in our sample can also be a consequence of our method to create the frequency information. The different approaches and strictness of classification may cause a variety of frequency information. Furthermore, research evidence implies that the severity of cyberbullying might be a better source of information than the frequency answer options of questionnaires (Várnai et al., 2018). However, another reason of underreported cyberbullying involvement might be that in some cases, teachers were also present when the study was conducted. Further, it is important to be noted that the $R$ squared and standardized beta estimates are weak both in the linear regression analyses and the path model analyses, though the models show significant results and excellent fitting indices. This implies that though there is a relationship among the variables, the independent variables do not predict the dependent variables precisely. This can be a consequence of high variability in the dataset, and that the data violates the normality assumptions. The reliability score of enmeshed family cohesion (FACES IV) was also quite low; this also could affect the $R$ squared and standardized beta estimates. Thus, the results regarding this scale should be interpreted carefully. Additionally, the low frequency of cyberbullying involvement in our sample can also be a possible cause of the weak $R$ squared and standardized beta estimates. Moreover, on account of the cross-sectional design of our study, we could not examine the long-term effects of family and peer factors and emotion regulation. In order to have a better understanding of how family cohesion and adaptation changes during the course of adolescence and how these dynamics affect cyberbullying involvement, longitudinal research design is needed. Further, it would be important to examine the parents' knowledge about technology and their strategies to restrict or mediate the youngsters' Internet use; this could also contribute to a better understanding of our results.

\section{Conclusions}

Overall, our results demonstrated the importance of family cohesion, perceived parental and peer support and emotion regulation in both cyberbullying perpetration and cybervictimization. However, the weak estimates imply that there may be other influencing factors that were not included in our research. These factors could be important in the understanding and tackling of cyberbullying. Therefore, it would be important to continue this line of research. Future research could use Bronfenbrenner's ecological systems theory (1989) and include more variables from the individual (e.g. moral and socio-emotional skills), microsystem (e.g. school climate), mesosystem (e.g. socioeconomic status), exosystem (e.g. community or media attitudes toward cyberbullying) and macrosystem (e.g. cultural attitude towards bullying behaviour) levels. The usage of the different levels and exploring their influences on cyberbullying engagement could result in a deeper understanding about the underlying dynamics of cyberbullying. Further, our results support the importance of involving family and peer relationships in the prevention/intervention programs. As well as, the results imply the significance of helping adolescents to understand their emotions and to regulate their impulses in order to prevent their cyberbullying involvement. Although, our results show that not only these factors are influencing cyberbullying engagement, so the continuation of research is also important from a practical viewpoint. Future findings about other significant influencing factors could help the development of effective prevention and intervention programs. At last, strength of our research is that our results contribute to a more dynamic viewpoint of cyberbullying behaviours and might help the beginning of a new direction in cyberbullying research. 
Author Contribution Conceptualization: NA, BL. Methodology: NA, BL. Formal analysis and investigation: NA, ANZs, AR. Writingoriginal draft preparation: NA. Writing-review and editing: NA, BL, ANZs, BP. Funding acquisition: NA, AR, ANZs, BP, BL. Supervision: BL, ANZs, BP.

Funding Open access funding provided by University of Pécs. The paper has been supported by EFOP-3.6.1.-16-2016-00004 "Comprehensive Development for Implementing Smart Specialization Strategies at the University of Pécs and ÚNKP-19-3-I-PTE-156, New National Excellence Program of the Ministry for Innovation and Technology.

Data Availability All data are analysed during the current study are available in the article.

\section{Declarations}

Conflict of Interest The authors declare no competing interests.

Open Access This article is licensed under a Creative Commons Attribution 4.0 International License, which permits use, sharing, adaptation, distribution and reproduction in any medium or format, as long as you give appropriate credit to the original author(s) and the source, provide a link to the Creative Commons licence, and indicate if changes were made. The images or other third party material in this article are included in the article's Creative Commons licence, unless indicated otherwise in a credit line to the material. If material is not included in the article's Creative Commons licence and your intended use is not permitted by statutory regulation or exceeds the permitted use, you will need to obtain permission directly from the copyright holder. To view a copy of this licence, visit http://creativecommons.org/licenses/by/4.0/.

\section{References}

Alhujailli, A., Karwowski, W., Wan, T. T., \& Hancock, P. (2020). Affective and stress consequences of cyberbullying. Symmetry, 12(9), 1536.

Altman, D. G., \& Bland, J. M. (1995). Statistics notes: the normal distribution. Bmj, 310(6975), 298.

Álvarez-García, D., Pérez, J. C. N., González, A. D., \& Pérez, C. R. (2015). Risk factors associated with cybervictimization in adolescence. International Journal of Clinical and Health Psychology, 15(3), 226-235.

Arató, N., Zsidó, A. N., Lénárd, K., \& Lábadi, B. (2019). Az internetes zaklatás áldozata és elkövetője kérdőív (CVBS-HU) és az Európai Cyberbullying Intervenciós Projekt Kérdőív (ECIPQ) magyar adaptációja. Iskolakultúra, 29(12), 81-110.

Baiocco, R., Cacioppo, M., Laghi, F., \& Tafà, M. (2013). Factorial and construct validity of FACES IV among Italian adolescents. Journal of Child and Family Studies, 22(7), 962-970.

Banerjee, R., Robinson, C., \& Smalley, D. (2010). Evaluation of the Beatbullying peer mentoring programme. Report for Beatbullying. University of Sussex.

Baldry, A. C., Farrington, D. P., \& Sorrentino, A. (2015). "Am I at risk of cyberbullying"? A narrative review and conceptual framework for research on risk of cyberbullying and cybervictimization: The risk and needs assessment approach. Aggression and Violent Behavior, 23, 36-51.

Baroncelli, A., \& Ciucci, E. (2014). Unique effects of different components of trait emotional intelligence in traditional bullying and cyberbullying. Journal of Adolescence, 37(6), 807-815.

Baron, R. M., \& Kenny, D. A. (1986). The moderator-mediator variable distinction in social psychological research: conceptual, strategic, and statistical considerations. Journal of Personality and Social Psychology, 51(6), 1173.

Bayraktar, F., Machackova, H., Dedkova, L., Cerna, A., \& Ševčíková, A. (2015). Cyberbullying: the discriminant factors among cyberbullies, cybervictims, and cyberbully-victims in a Czech adolescent sample. Journal of Interpersonal Violence, 30(18), 3192-3216.

Beran, T., \& Li, Q. (2005). Cyber-harassment: a study of a new method for an old behavior. Journal of Educational Computing Research, 32(3), 265.

Beran, T., \& Li, Q. (2007). The relationship between cyberbullying and school bullying. The Journal of Student Wellbeing, 1(2), 16-33.

Berne, S., Frisén, A., Schultze-Krumbholz, Scheithauer, H., Naruskov, K., Luik, P., Katzer, C. A., Erentaite, R., \& Zukauskiene, R. (2013). Cyberbullying assessment instruments: a systematic review. Agression and Violent Behavior, 18, 320-334.

Bronfenbrenner, U. (1989). Ecological systems theory. In R. Vasta (Ed.) Annals of Child Development (pp. 197-249). JAI Press.

Buelga, S., Martínez-Ferrer, B., \& Cava, M. J. (2017). Differences in family climate and family communication among cyberbullies, cybervictims, and cyber bully-victims in adolescents. Computers in Human Behavior, 76, 164-173.

Buelga, S., Martínez-Ferrer, B., \& Musitu, G. (2016). Family relationships and cyberbullying. In R. Navarro, S. Yubero, \& E. Larranga (Eds.), Cyberbullying Across the Globe: Gender, Family, and Mental Health (pp. 99-114). Springer International Publishing.

Cashwell, C. S., \& Vacc, N. A. (1996). Family functioning and risk behaviors: influences on adolescent delinquency. The School Counselor, 44(2), 105-114.

Calvete, E., Orue, I., Estévez, A., Villardón, L., \& Padilla, P. (2010). Cyberbullying in adolescents: modalities and aggressors' profile. Computers in Human Behavior, 26(5), 1128-1135.

Cho, Y. K., \& Yoo, J. W. (2017). Cyberbullying, internet and SNS usage types, and perceived social support: a comparison of different age groups. Information, Communication \& Society, 20(10), 1464-1481.

Cooke, B. D., Rossmann, M. M., McCubbin, H. I., \& Patterson, J. M. (1988). Examining the definition and assessment of social support: a resource for individuals and families. Family relations, 211-216.

Cross, D., Barnes, A., Papageorgiou, A., Hadwen, K., Hearn, L., \& Lester, L. (2015). A social-ecological framework for understanding and reducing cyberbullying behaviours. Aggression and Violent Behavior, 23, 109-117.

Del Rey, R., Casas, J. A., Ortega-Ruiz, R., Schultze-Krumbholz, A., Scheitauer, H., Smith, P., Thompson, F., Barkoukis, V., Tsorbatzoudis, H., Brighi, A., Guarini, A., Pyzalski, J., \& Plichta, P. (2015). Structural validation and cross-cultural robustness of the European Cyberbullying Intervention Project Questionnaire. Computers in Human Behavior, 50, 141-147.

Den Hamer, A. H., \& Konijn, E. A. (2016). Can emotion regulation serve as a tool in combating cyberbullying? Personality and Individual Differences, 102, 1-6.

Didden, R., Scholte, R. H., Korzilius, H., De Moor, J. M., Vermeulen, A., O'Reilly, M., Lang, R., \& Lancioni, G. E. (2009). Cyberbullying among students with intellectual and developmental disability in special education settings. Developmental Neurorehabilitation, 12(3), 146-151.

Dodge, K. A., Coie, J. D., \& Lynam, D. (2007). Aggression and antisocial behavior in youth. In N. Eisenberg (Ed.) Handbook of Child Psychology, 3 (pp. 719-788). Wiley.

Dunn, J., \& Brown, J. (1991). Relationships, talk about feelings, and the development of affect regulation in early childhood. In J. Garber \& K. A. Dodge (Eds.), Cambridge studies in social and emotional development. The development of emotion regulation and dysregulation (p. 89-108). Cambridge University Press.

Eisenberg, N., Cumberland, A., \& Spinrad, T. L. (1998). Parental socialization of emotion. Psychological Inquiry, 9(4), 241-273. 
Eisenberg, N., \& Fabes, R. A. (1992). Emotion, regulation, and the development of social competence. In M. S. Clark (Ed.), Review of Personality and Social Psychology: Emotion and Social Behavior (pp. 119-150). Sage Publications Inc.

Elgar, F. J., Napoletano, A., Saul, G., Dirks, M. A., Craig, W., Poteat, V. P., Holt, M., \& Koenig, B. W. (2014). Cyberbullying victimization and mental health in adolescents and the moderating role of family dinners. JAMA Pediatrics, 168(11), 1015-1022.

Elliott, A. C., \& Woodward, W. A. (2007). Statistical analysis quick reference guidebook: with SPSS examples. Sage.

Fanti, K. A., Demetriou, A. G., \& Hawa, V. V. (2012). A longitudinal study of cyberbullying: examining riskand protective factors. European Journal of Developmental Psychology, 9(2), 168-181.

Fridh, M., Lindström, M., \& Rosvall, M. (2015). Subjective health complaints in adolescent victims of cyber harassment: moderation through support from parents/friends-a Swedish populationbased study. BMC Public Health, 15(1), 949.

Ghasemi, A., \& Zahediasl, S. (2012). Normality tests for statistical analysis: a guide for non-statisticians. International Journal of Endocrinology and Metabolism, 10(2), 486.

Gianesini, G., \& Brighi, A. (2015). Cyberbullying in the era of digital relationships: the unique role of resilience and emotion regulation on adolescents' adjustment. Sociological Studies of Children and Youth, 19, 1-46.

Gottman, J. M., \& Mettetal, G. (1986). Speculations about social and affective development: friendship and acquaintanceship through adolescence. In J. M. Gottman \& J. G. Parker (Eds.), Studies in emotion and social interaction. Conversations of friends: Speculations on affective development (p. 192-237). Cambridge University Press.

Gratz, K. L., \& Roemer, L. (2004). Multidimensional assessment of emotion regulation and dysregulation: development, factor structure, and initial validation of the difficulties in emotion regulation scale. Journal of Psychopathology and Behavioral Assessment, 26(1), 41-54.

Gross, E. F. (2004). Adolescent Internet use: what we expect, what teens report. Journal of Applied Developmental Psychology, 25(6), 633-649.

Gross, J. J., \& John, O. P. (2003). Individual differences in two emotion regulation processes: implications for affect, relationships, and well-being. Journal of Personality and Social Psychology, 85(2), 348-362.

Hartup, W. W., \& Stevens, N. (1997). Friendships and adaptation in the life course. Psychological Bulletin, 121(3), 355-370.

Hellfeldt, K., López-Romero, L., \& Andershed, H. (2020). Cyberbullying and psychological well-being in young adolescence: the potential protective mediation effects of social support from family, friends, and teachers. International Journal of Environmental Research and Public Health, 17(1), 45.

Hemphill, S. A., \& Heerde, J. A. (2014). Adolescent predictors of young adult cyberbullying perpetration and victimization among Australian youth. Journal of Adolescent Health, 55(4), 580-587.

Heerde, J. A., \& Hemphill, S. A. (2018). Examination of associations between informal help-seeking behavior, social support, and adolescent psychosocial outcomes: a meta-analysis. Developmental Review, 47, 44-62.

Hirsch, B. J. (1981). Social networks and the coping process: creating personal communities. In B. Gottlieb (Ed.) Social Networks and Social Support (pp. 149-170). Sage Publications.

Hu, L., \& Bentler, P. M. (1999). Cutoff criteria for fit indexes incovariance structure analysis: conventional criteria versus new alternatives. Structural Equation Modeling: A Multidisciplinary Journal, 6, 1-55.

Jenkins, L. N., \& Demaray, M. K. (2012). Social support and selfconcept in relation to peer victimization and peer aggression. Journal of School Violence, 11(1), 56-74.
Koutra, K., Triliva, S., Roumeliotaki, T., Lionis, C., \& Vgontzas, A. N. (2013). Cross-cultural adaptation and validation of the Greek version of the Family Adaptability and Cohesion Evaluation Scales IV Package (FACES IV Package). Journal of Family Issues, 34(12), 1647-1672.

Kowalski, R. M., Giumetti, G. W., Schroeder, A. N., \& Lattanner, M. R. (2014). Bullying in the digital age: a critical review and metaanalysis of cyberbullying research among youth. Psychological Bulletin, 140(4), 1073-1137.

Kowalski, R. M., \& Limber, S. P. (2007). Electronic bullying among middle school students. Journal of Adolescent Health, 41(6), S22-S30.

Kowalski, R. M., \& Limber, S. P. (2013). Psychological, physical, and academic correlates of cyberbullying and traditional bullying. Journal of Adolescent Health, 53(1), S13-S20.

Kökönyei, Gy. (2008). Érzelemszabályozás krónikus fájdalomban (Unpublished doctoral dissertation). Eötvös Loránd University.

Kwan, G. C. E., \& Skoric, M. M. (2013). Facebook bullying: an extension of battles in school. Computers in Human Behavior, 29, $16-25$.

Larrañaga, E., Yubero, S., Ovejero, A., \& Navarro, R. (2016). Loneliness, parent-child communication and cyberbullying victimization among Spanish youths. Computers in Human Behavior, 65, $1-8$.

Li, Q. (2007). Bullying in the new playground: research into cyberbullying and cyber victimisation. Australasian Journal of Educational Technology, 23(4).

López, E. E., Pérez, S. M., Ochoa, G. M., \& Ruiz, D. M. (2008). Adolescent aggression: effects of gender and family and school environments. Journal of Adolescence, 31(4), 433-450.

MacKinnon, D. P., Lockwood, C. M., \& Williams, J. (2004). Confidence limits for the indirect effect: distribution of the product and resampling methods. Multivariate Behavioral Research, 39(1), 99-128.

Martins, M. D., Veiga Simao, A. M., Freire, I., Caetano, A. P., \& Matos, A. (2016). Cybervictimization and cyber-aggression among Portugese adolescents: the relation to family support and family rules. International Journal of Cyber Behavior, Psychology and Learning, 6(3), 65-78.

McCubbin, H. I., Joy, C. B., Cauble, A. E., Comeau, J. K., Patterson, J. M., \& Needle, R. H. (1980). Family stress and coping decade review. Journal of Marriage and the Family, 42, 855-871.

Mesch, G. S. (2009). Parental mediation, online activities, and cyberbullying. CyberPsychology \& Behavior, 12(4), 387-393.

Mishna, F., Khoury-Kassabri, M., Gadalla, T., \& Daciuk, J. (2012). Risk factors for involvement in cyber bullying: victims, bullies and bully-victims. Children and Youth Services Review, 34(1), 63-70.

Morris, A. S., Silk, J. S., Steinberg, L., Myers, S. S., \& Robinson, L. R. (2007). The role of the family context in the development of emotion regulation. Social Development, 16(2), 361-388.

Nocentini, A., Calmaestra, J., Schultze-Krumbholz, A., Scheithauer, H., Ortega, R., \& Menesini, E. (2010). Cyberbullying: labels, behaviours and definition in three European countries. Australian Journal of Guidance and Counselling, 20(2), 129.

Olenik-Shemesh, D., \& Heiman, T. (2017). Cyberbullying victimization in adolescents as related to body esteem, social support, and social self-efficacy. The Journal of Genetic Psychology, 178(1), $28-43$.

Olson, D. H. (2000). Circumplex model of marital and family systems. Journal of Family Therapy, 22(2), 144-167.

Olson, D. (2011). FACES IV and the circumplex model: validation study. Journal of Marital and Family Therapy, 37(1), 64-80.

Olweus, D. (1994). Bullying at school: long-term outcomes for the victims and an effective school-based intervention program. In L. R. Huesmann (Ed.), Aggressive Behavior: Current Perspectives (pp. 97-130). Plenum Press. 
Ortega-Barón, J., Buelga-Vasquez, S., \& Cava-Caballero, M. J. (2016). The influence of school climate and family climate among adolescents victims of cyberbullying. Comunicar, 24(46), 57-65.

Ortega, R., Elipe, P., Mora-Merchán, J. A., Genta, M. L., Brighi, A., Guarini, A., Smith, P. K., Thompson, F., \& Tippett, N. (2012). The emotional impact of bullying and cyberbullying on victims: a European cross-national study. Aggressive Behavior, 38(5), 342-356.

Papp-Zipernovszky, O., Kékesi, M. Z., \& Jámbori, S. (2017). Validation of the Hungarian version of Multidimensional Scale of Perceived Social Support. Mentálhigiéné és Pszichoszomatika, 18(3), 230-262.

Pérez-Fuentes, M. D. C., Molero Jurado, M. D. M., Barragán Martín, A. B., \& Gázquez Linares, J. J. (2019). Family functioning, emotional intelligence, and values: analysis of the relationship with aggressive behavior in adolescents. International Journal of Environmental Research and Public Health, 16(3), 478-492.

Perren, S., Corcoran, L., Cowie, H., Dehue, F., Garcia, D., McGuckin, C., Sevcikova, A., Tsatsou, P., \& Völlink, T. (2012). Tackling cyberbullying: review of empirical evidence regarding successful responses by students, parents, and schools. International Journal of Conflict and Violence, 6(2), 283-292.

Perren, S., Dooley, J., Shaw, T., \& Cross, D. (2010). Bullying in school and cyberspace: associations with depressive symptoms in Swiss and Australian adolescents. Child and Adolescent Psychiatry and Mental Health, 4(1), 28.

Place, M., Hulsmeier, J., Brownrigg, A., \& Soulsby, A. (2005). The Family Adaptability and Cohesion Evaluation Scale (FACES): an instrument worthy of rehabilitation? Psychiatric Bulletin, 29(6), $215-218$.

Quoidbach, J., Berry, E. V., Hansenne, M., \& Mikolajczak, M. (2010). Positive emotion regulation and well-being: comparing the impact of eight savoring and dampening strategies. Personality and Individual Differences, 49(5), 368-373.

Roberton, T., Daffern, M., \& Bucks, R. S. (2012). Emotion regulation and aggression. Aggression and Violent Behavior, 17(1), 72-82.

Rutherford, H. J., Wallace, N. S., Laurent, H. K., \& Mayes, L. C. (2015). Emotion regulation in parenthood. Developmental Review, 36, 1-14.

Schneider, S. K., O’Donnell, L., Stueve, A., \& Coulter, R. W. (2012). Cyberbullying, school bullying, and psychological distress: a regional census of high school students. American Journal of Public Health, 102(1), 171-177.

Shahar, G., \& Henrich, C. C. (2016). Perceived family social support buffers against the effects of exposure to rocket attacks on adolescent depression, aggression, and severe violence. Journal of Family Psychology, 30(1), 163-168.

Skilbred-Fjeld, S., Reme, S. E., \& Mossige, S. (2020). Cyberbullying involvement and mental health problems among late adolescents. Cyberpsychology: Journal of Psychosocial Research on Cyberspace, 14(1).

Slonje, R., \& Smith, P. K. (2008). Cyberbullying: another main type of bullying? Scandinavian Journal of Psychology, 45(2), 147-154.

Smith, P. K., Mahdavi, J., Carvalho, M., Fisher, S., Russel, S., \& Tippett, N. (2008). Cyberbullying: its nature and impact in secondary school pupils. Journal of Child Psychology and Psychiatry, 49, 376-385.

Solecki, S., McLaughlin, K., \& Goldschmidt, K. (2014). Promoting positive offline relationships to reduce negative online experiences. Journal of Pediatric Nursing, 29(5), 482-484.

Spears, B., Slee, P., Owens, L., \& Johnson, B. (2009). Behind the scenes and screens: insights into the human dimension of covert and cyberbullying. Zeitschrift für Psychologie/Journal of Psychology, 217(4), 189.
Sroufe, L. A., Schrok, E., Motti, R., Lawroski, N., \& C LaFreniere, P. (1984). The role of affect in social competence. In C. E. Izard, J. Kagan, \& R. B. Zajonc (Eds.) Emotions, Cognition, and Behavior (pp. 289-319). Cambridge University Press.

Steinberg, L. (2000). The family at adolescence: transition and transformation. Journal of Adolescent Health, 27(3), 170-178.

Steinberg, L., \& Silk, J. S. (2002). Parenting adolescents. In. M. H. Bornsetein (Ed.), Handbook of Parenting, 1, (pp. 103-133.) Mahwah, NJ: Lawrence Erlbaum Associates.

Taiariol, J. (2010). Cyberbullying: The role of family and school. Wayne State University Dissertations. Paper 118.

Thompson, F., \& Smith, P. K. (2011). The use and effectiveness of antibullying strategies in schools. Research Brief DFE-RR098, 1-220.

Valkenburg, P. M., \& Peter, J. (2007). Preadolescents' and adolescents' online communication and their closeness to friends. Developmental Psychology, 43(2), 267.

Van Dijk, M. P., Branje, S., Keijsers, L., Hawk, S. T., Hale, W. W., \& Meeus, W. (2014). Self concept clarity across adolescence: Longitudinal associations with open communication with parents and internalizing symptoms. Journal of Youth and Adolescence, 43(11), 1861-1876.

Vargha, A., \& Tóth, M. (2007). Az Olson-féle családteszt magyar adaptációja. In. Bagdy E., Mirnics, Zs., Vargha A. (Eds.) Egyén, pár, család (pp. 288-309). Animula.

Várnai D. E., Jármi, É., Arnold, P., Demetrovics ZS., Németh Á., Kökönyei Gy., \& Örkényi Á. (2018). A kortársbántalmazás (bullying) értelmezésének vizsgálata kvalitatív módszerrel - “Az iskoláskorú gyerekek egészségmagatartása" (HBSC) vizsgálat módszertanának kiegészítésére. Magyar Pszichológiai Szemle, 73, 519-539.

Vazsonyi, A. T., Machackova, H., Sevcikova, A., Smahel, D., \& Cerna, A. (2012). Cyberbullying in context: direct and indirect effects by low self-control across 25 European countries. European Journal of Developmental Psychology, 9(2), 210-227.

Vranjes, I., Erreygers, S., Vandebosch, H., Baillien, E., \& De Witte, H. (2018). Patterns of cybervictimization and emotion regulation in adolescents and adults. Aggressive Behavior, 44(6), 647-657.

Walrave, M., \& Heirman, W. (2011). Cyberbullying: predicting victimisation and perpetration. Children \& Society, 25(1), 59-72.

Wang, J., Iannotti, R. J., Luk, J. W., \& Nansel, T. R. (2010). Co-occurrence of victimization from five subtypes of bullying: physical, verbal, social exclusion, spreading rumors, and cyber. Journal of Pediatric Psychology, 35(10), 1103-1112.

Wang, J., Iannotti, R. J., \& Nansel, T. R. (2009). School bullying among adolescents in the United States: physical, verbal, relational, and cyber. Journal of Adolescent Health, 45(4), 368-375.

Williams, K. R., \& Guerra, N. G. (2007). Prevalence and predictors of internet bullying. Journal of Adolescent Health, 41(6), 14-21.

Wolak, J., Mitchell, K. J., \& Finkelhor, D. (2003). Escaping or connecting? Characteristics of youth who form close online relationships. Journal of Adolescence, 26(1), 105-119.

Ybarra, M. L., Diener-West, M., \& Leaf, P. J. (2007). Examining the overlap in Internet harassment and school bullying: implications for school intervention. Journal of Adolescent health, 41(6), S42-S50.

Ybarra, M. L., \& Mitchell, K. J. (2004). Online aggressor/targets, aggressors, and targets: a comparison of associated youth characteristics. Journal of Child Psychology and Psychiatry, 45(7), 1308-1316.

Zimet, G. D., Dahlem, N. W., Zimet, S. G., \& Farley, G. K. (1988). The multidimensional scale of perceived social support. Journal of Personality Assessment, 52(1), 30-41.

Zimet, G. D., Powell, S. S., Farley, G. K., Werkman, S., \& Berkoff, K. A. (1990). Psychometric characteristics of the multidimensional scale of perceived social support. Journal of personality assessment, 55(3-4), 610-617. 